\title{
Beyond RuBisCO: Convergent molecular evolution of multiple chloroplast genes in $\mathrm{C}_{4}$ plants
}

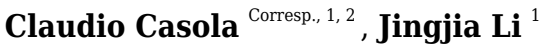 \\ ${ }^{1}$ Department of Ecology and Conservation Biology, Texas A\&M University, College Station, Texas, United States \\ 2 Interdisciplinary Graduate Program in Ecology and Evolutionary Biology, Texas A\&M University, College Station, Texas, United States \\ Corresponding Author: Claudio Casola \\ Email address: ccasola@tamu.edu
}

Background. The recurrent evolution of the $\mathrm{C}_{4}$ photosynthetic pathway in angiosperms represents one of the most extraordinary examples of convergent evolution of a complex trait. Comparative genomic analyses have unveiled some of the molecular changes associated with the $\mathrm{C}_{4}$ pathway. For instance, several key enzymes involved in the transition from $C_{3}$ to $C_{4}$ photosynthesis have been found to share convergent amino acid replacements along $\mathrm{C}_{4}$ lineages. However, the extent of convergent replacements potentially associated with the emergence of $\mathrm{C}_{4}$ plants remains to be fully assessed. Here, we conducted an organelle-wide analysis to determine if convergent evolution occurred in multiple chloroplast proteins beside the well-known case of the large RuBisCO subunit encoded by the chloroplast gene rbcL.

Methods. Our study was based on the comparative analysis of $43 \mathrm{C}_{4}$ and $21 \mathrm{C}_{3}$ grass species belonging to the PACMAD clade, a focal taxonomic group in many investigations of $\mathrm{C}_{4}$ evolution. We first used protein sequences of 67 orthologous chloroplast genes to build an accurate phylogeny of these species. Then, we inferred amino acid replacements along $13 C_{4}$ lineages and $9 C_{3}$ lineages using reconstructed protein sequences of their reference branches, corresponding to the branches containing the most recent common ancestors of C4-only clades and C3-only clades. Pairwise comparisons between reference branches allowed us to identify both convergent and non-convergent amino acid replacements between $\mathrm{C}_{4}: \mathrm{C}_{4}, \mathrm{C}_{3}: \mathrm{C}_{3}$ and $\mathrm{C}_{3}: \mathrm{C}_{4}$ lineages.

Results. The reconstructed phylogenetic tree of 64 PACMAD grasses was characterized by strong supports in all nodes used for analyses of convergence. We identified 217 convergent replacements and 201 non-convergent replacements in 45/67 chloroplast proteins in both $\mathrm{C}_{4}$ and $\mathrm{C}_{3}$ reference branches. $\mathrm{C}_{4}: \mathrm{C}_{4}$ branches showed higher levels of convergent replacements than $\mathrm{C}_{3}: \mathrm{C}_{3}$ and $\mathrm{C}_{3}: \mathrm{C}_{4}$ branches. Furthermore, we found that more proteins shared unique convergent replacements in $\mathrm{C}_{4}$ lineages, with both RbcL and RpoC1 (the RNA polymerase beta' subunit 1) showing a significantly higher convergent/non-convergent replacements ratio in $\mathrm{C}_{4}$ branches. Notably, more $\mathrm{C}_{4}: \mathrm{C}_{4}$ reference branches showed higher numbers of convergent vs. non-convergent replacements than $C_{3}: C_{3}$ and $C_{3}: C_{4}$ branches. Our results suggest that, in the PACMAD clade, $\mathrm{C}_{4}$ grasses experienced higher levels of molecular convergence than $\mathrm{C}_{3}$ species across multiple chloroplast genes. These findings have important implications for our understanding of the evolution of the $\mathrm{C}_{4}$ photosynthesis pathway. 
1 Beyond RuBisCO: Convergent molecular evolution of multiple chloroplast genes in $\mathrm{C}_{4}$

2 plants

3 Claudio Casola ${ }^{1,2}$, Jingjia $\mathrm{Li}^{1}$

$4{ }^{1}$ Department of Ecology and Conservation Biology, Texas A\&M University, College Station, 5 TX, USA

$6{ }^{2}$ Interdisciplinary Graduate Program in Ecology and Evolutionary Biology, Texas A\&M

7 University, College Station, TX, USA

8

9 Corresponding author:

10 Claudio Casola

11534 John Kimbrough Blvd, College Station, TX 77843, USA

12 Email address: claudio.casola@ag.tamu.edu

13

14 
15 Abstract

16 Background. The recurrent evolution of the $\mathrm{C}_{4}$ photosynthetic pathway in angiosperms

17 represents one of the most extraordinary examples of convergent evolution of a complex trait.

18 Comparative genomic analyses have unveiled some of the molecular changes associated with the

$19 \mathrm{C}_{4}$ pathway. For instance, several key enzymes involved in the transition from $\mathrm{C}_{3}$ to $\mathrm{C}_{4}$

20 photosynthesis have been found to share convergent amino acid replacements along $\mathrm{C}_{4}$ lineages.

21 However, the extent of convergent replacements potentially associated with the emergence of $\mathrm{C}_{4}$

22 plants remains to be fully assessed. Here, we conducted an organelle-wide analysis to determine

23 if convergent evolution occurred in multiple chloroplast proteins beside the well-known case of

24 the large RuBisCO subunit encoded by the chloroplast gene $r b c L$.

25 Methods. Our study was based on the comparative analysis of $43 \mathrm{C}_{4}$ and $21 \mathrm{C}_{3}$ grass species

26 belonging to the PACMAD clade, a focal taxonomic group in many investigations of $\mathrm{C}_{4}$

27 evolution. We first used protein sequences of 67 orthologous chloroplast genes to build an

28 accurate phylogeny of these species. Then, we inferred amino acid replacements along $13 \mathrm{C}_{4}$

29 lineages and $9 \mathrm{C}_{3}$ lineages using reconstructed protein sequences of their reference branches,

30 corresponding to the branches containing the most recent common ancestors of C4-only clades

31 and C3-only clades. Pairwise comparisons between reference branches allowed us to identify

32 both convergent and non-convergent amino acid replacements between $\mathrm{C}_{4}: \mathrm{C}_{4}, \mathrm{C}_{3}: \mathrm{C}_{3}$ and $\mathrm{C}_{3}: \mathrm{C}_{4}$

33 lineages.

34 Results. The reconstructed phylogenetic tree of 64 PACMAD grasses was characterized by

35 strong supports in all nodes used for analyses of convergence. We identified 217 convergent

36 replacements and 201 non-convergent replacements in 45/67 chloroplast proteins in both $\mathrm{C}_{4}$ and

$37 \mathrm{C}_{3}$ reference branches. $\mathrm{C}_{4}: \mathrm{C}_{4}$ branches showed higher levels of convergent replacements than

$38 \mathrm{C}_{3}: \mathrm{C}_{3}$ and $\mathrm{C}_{3}: \mathrm{C}_{4}$ branches. Furthermore, we found that more proteins shared unique convergent

39 replacements in $\mathrm{C}_{4}$ lineages, with both $\mathrm{RbcL}$ and $\mathrm{RpoC} 1$ (the RNA polymerase beta' subunit 1)

40 showing a significantly higher convergent/non-convergent replacements ratio in $\mathrm{C}_{4}$ branches.

41 Notably, more $\mathrm{C}_{4}: \mathrm{C}_{4}$ reference branches showed higher numbers of convergent vs. non-

42 convergent replacements than $\mathrm{C}_{3}: \mathrm{C}_{3}$ and $\mathrm{C}_{3}: \mathrm{C}_{4}$ branches. Our results suggest that, in the

43 PACMAD clade, $\mathrm{C}_{4}$ grasses experienced higher levels of molecular convergence than $\mathrm{C}_{3}$ species

44 across multiple chloroplast genes. These findings have important implications for our

45 understanding of the evolution of the $\mathrm{C}_{4}$ photosynthesis pathway.

46 
Introduction

49 Convergent evolution represents the independent acquisition of similar phenotypic traits in

50 phylogenetically distant organisms. Understanding the genomic changes underlying the recurrent emergence of phenotypes is a major goal of molecular evolution. The rapidly increasing taxonomic breadth of genomic resources combined with the development of rigorous frameworks to comparatively investigate molecular changes has accelerated the pace of discovery in this area. For instance, substitutions in coding regions of conserved genes have been implicated in phenotypic changes responsible for adaptation of marine mammals to an aquatic lifestyle (Foote, et al. 2015; Zhou, et al. 2015). Other examples of convergent phenotypes whose molecular underpinnings have been investigated include adaptations in snake and agamid lizard mitochondria (Castoe, et al. 2009), echolocation in mammals (Parker, et al. 2013; Thomas and Hahn 2015; Zou and Zhang 2015; Storz 2016), and hemoglobin function in birds (Natarajan, et al. 2016). Convergent traits can evolve via changes toward the same derived state (similar phenotype) from the same initial state, which is known as parallelism, or through changes of different initial states, referred to as convergence (Zhang and Kumar 1997; Storz 2016). For the sake of simplification, we will refer to these two processes using the general terminology 'convergence' and 'convergent replacements' throughout the manuscript, unless differently stated.

Several traits are also known to have convergently evolved in land plants (Li, et al. 2018; Lu, et al. 2018; Preite, et al. 2019). One of the most notable examples is represented by the repeated evolution of the $\mathrm{C}_{4}$ photosynthetic pathway in flowering plants. The $\mathrm{C}_{4}$ pathway is a complex functional adaptation that allows for better photosynthesis efficiency under certain environmental conditions, such as dry and warm climates, high light intensity, low $\mathrm{CO}_{2}$ concentration, and limited availability of nutrients (Knapp and Medina 1999; Long 1999). The $\mathrm{C}_{4}$ pathway involves cytological, anatomical and metabolic modifications thought to have evolved multiple times independently in various lineages from the $\mathrm{C}_{3}$ type (Kellogg 1999; Sage 2004; Sage, et al. 2011). According to phylogenetic, anatomical and biochemical evidence, the few slightly different variants of the $\mathrm{C}_{4}$ photosynthesis type evolved more than 60 times in angiosperms (Sage, et al. 2012; Heyduk, et al. 2019). In grasses (family Poaceae) alone, the $\mathrm{C}_{4}$ pathway has evolved independently 20 times (Grass Phylogeny Working Group 2012). nonsynonymous substitutions, gene duplications and gene expression alterations (Christin, et al. 2007; Christin, Boxall, et al. 2013; Christin, et al. 2015; Goolsby, et al. 2018; Heyduk, et al. 2019). It has been suggested that the evolution of the $\mathrm{C}_{4}$ pathways proceeded throughout a series of evolutionary steps wherein the Kranz leaf anatomy typical of this pathway originated first, followed by changes in the expression patterns of key genes and finally by adaptive modifications of protein sequences (Sage, et al. 2012; Christin, Osborne, et al. 2013; Williams, et al. 2013). A model of the adaptive steps leading to $\mathrm{C}_{4}$ photosynthesis showed that key 
88 biochemical components of this pathway evolved modularly along a trajectory that was likely very similar across lineages with $\mathrm{C}_{3}$ to $\mathrm{C}_{4}$ transitions (Heckmann, et al. 2013). Overall, these scenarios suggest that enzymes involved in $\mathrm{C}_{3}$ to $\mathrm{C}_{4}$ transitions experienced similar selective pressures that resulted in the convergent evolution of the same amino acid replacements across $\mathrm{C}_{4}$ lineages.

93

Evidence of convergent changes in proteins associated with photosynthetic processes has steadily accumulated since genomic data from multiple $\mathrm{C}_{4}$ lineages have become available in the past couple of decades. Most of these studies have focused on the ribulose-1,5-bisphosphate carboxylase/oxygenase (RuBisCO), a large multimeric enzyme that catalyzes the carboxylation of ribulose-1,5-bisphosphate (RuBP), allowing plants to fix atmospheric carbon (Andersson and Backlund 2008). RuBisCO also catalyzes oxygenation of RuBP, which leads to loss of carbon in the process of photorespiration (Andersson and Backlund 2008; Maurino and Peterhansel 2010). RuBisCO's limited ability to discriminate between $\mathrm{CO}_{2}$ and $\mathrm{O}_{2}$ has been attributed to the much higher $\mathrm{CO}_{2}$ to $\mathrm{O}_{2}$ atmospheric partial pressure until 400 million years ago (Sage 1999, 2004; Sage, et al. 2012).

Previous studies have revealed multiple convergent amino acid replacements in the large RuBisCO subunit in $\mathrm{C}_{4}$ lineages, encoded by the chloroplast gene $r b c L$ (Kapralov and Filatov 2007; Christin, et al. 2008; Kapralov, et al. 2011; Kapralov, et al. 2012; Piot, et al. 2018). Some of these convergent replacements have been associated to positive selection of the corresponding codons in $\mathrm{C}_{4}$ monocot and eudicot lineages (Kapralov and Filatov 2007; Christin, et al. 2008; Kapralov, et al. 2012; Piot, et al. 2018). Notably, biochemical analyses have demonstrated that some recurrent amino acid changes in the large $\mathrm{RuBisCO}$ subunit of $\mathrm{C}_{4}$ plants critically alter the kinetics of RuBisCO, resulting in an accelerated rate of $\mathrm{CO}_{2}$ fixation at the beginning of the Calvin-Benson cycle (Studer, et al. 2014; Bouvier, et al. 2021). Convergent amino acid changes have also been described in enzymes that are encoded by nuclear genes and play a primary role in the $\mathrm{C}_{4}$ pathway, including the phosphoenolpyruvate carboxylase PEPC (Christin, et al. 2007; Besnard, et al. 2009), the NADP-malic enzymes NADP-me (Christin, Samaritani, et al. 2009), the phosphoenolpyruvate carboxykinase PEPCK (Christin, Petitpierre, et al. 2009) and the small RuBisCO subunit (Kapralov, et al. 2011).

Given the number of biochemical, physiological and anatomical traits that were affected in each evolutionary transition from $\mathrm{C}_{3}$ to $\mathrm{C}_{4}$ photosynthesis (Heyduk, et al. 2019), it is likely that many genes experienced analogous selective pressures across taxa that include $\mathrm{C}_{4}$ plants. This has been shown to be the case by Huang et al. (Huang, et al. 2017), who have developed an approach to identify potential genes involved in the transition to $\mathrm{C}_{4}$ photosynthesis using a genome-wide scan for selection along a phylogeny of PACMAD grasses. Of the 88 genes

127 known to have a role in $\mathrm{C}_{4}$ photosynthesis. Although this study did not focus on finding 
128 convergent replacements, it provided a comprehensive strategy and statistical testing framework

129 to identify novel genes that have likely played a role in the evolution of $\mathrm{C}_{4}$ grasses. It is possible

130 that a significant fraction of these genes accumulated convergent amino acid replacements during

$131 \quad \mathrm{C}_{3}$-to- $\mathrm{C}_{4}$ transitions.

132 Another recent, important work has produced the first analysis of convergent

133 replacements across multiple proteins involved in the metabolism of $\mathrm{C}_{4}$ and crassulacean acid

134 metabolism (CAM) among species belonging to the portullugo clade (Caryophyllales). Goolsby

135 and colleagues (2018) compared evolutionary patterns in 19 gene families with critical roles in

136 metabolic pathways of both $\mathrm{C}_{4}$ and CAM plants, also known as carbon-concentration

137 mechanisms (CCMs) genes, and in 64 non-CCM gene families. They found convergent

138 replacements in proteins from $\mathrm{C}_{4}$ and CAM lineages, as well as higher levels of convergent

139 replacements in CCM vs. non-CCM gene families (Goolsby, et al. 2018). Additionally, several

140 amino acid replacements that are prevalent among $\mathrm{C}_{4}$ and $\mathrm{CAM}$ taxa compared to $\mathrm{C}_{3}$ lineages

141 were identified in this study (Goolsby, et al. 2018).

142

Altogether, the results of this and other studies demonstrated that convergent molecular evolution occurred across multiple genes in both $\mathrm{C}_{4}$ and CAM groups. While significant progress has been made towards the detection of signatures of selection associated to the evolution of CCMs (Huang, et al. 2017; Piot, et al. 2018), a rigorous framework to assess the full extent of molecular convergence in $\mathrm{C}_{3}$ to $\mathrm{CCMs}$ transitions has yet to be presented. For example, analyses of convergent evolution should include null hypotheses that assume no differences between taxa with and without convergence. In the case of CCMs evolution, a plausible null hypothesis consists in statistically equivalent numbers of convergent replacements between $\mathrm{C}_{4}$ (or CAM) lineages and $\mathrm{C}_{3}$ lineages.

Additionally, nonadaptive replacements should be used to normalize convergent replacements, in order to account for variation in the rates of nonsynonymous substitutions across lineages. This approach has been successfully applied in studies of molecular convergent evolution in vertebrates by assessing both convergent replacements and protein sequence changes that result in different amino acids, or divergent replacements (Castoe, et al. 2009; Thomas and Hahn 2015; Zou and Zhang 2015). A broader definition of the latter group incorporates all replacements leading to different amino acids, regardless of their ancestral state. We refer to such changes as non-convergent replacements.

Furthermore, testing hypotheses about the extent of convergent molecular evolution remains particularly challenging for many nuclear genes, because of the prevalence of duplicated copies, particularly in plants (Christin, et al. 2007; Goolsby, et al. 2018). Single-copy nuclear or organelle genes allow to more easily recognize convergent changes and overcome possible confounding compensatory effects due to the presence of paralogous copies. 
Given these premises, we sought to test if convergent amino acid changes occur more frequently in proteins encoded by chloroplast genes in a taxon that includes multiple wellcharacterized lineages of $\mathrm{C}_{4}$ and $\mathrm{C}_{3}$ grasses. Chloroplast proteins represent an ideal set of targets to study the role of convergent evolution in $\mathrm{C}_{3}$ to $\mathrm{C}_{4}$ transitions for a variety of reasons. First, most chloroplast proteins are involved in biochemical and biophysical processes that are critical to photosynthesis. For instance, out of $\sim 75$ functionally annotated protein-coding genes in the maize chloroplast genome, 45 genes are implicated in photosynthesis-related processes, including $r b c L, 17$ genes coding for subunits of the photosystems I and II (PS I and PS II), 12 genes coding for subunits of the NADH dehydrogenase complex, 6 genes coding for chloroplast ATPase subunits, 4 genes coding for cytochrome b6f complex subunits, and a few more genes implicated in the assembly of other protein complexes (Maier, et al. 1995). Second, nonannotated orthologous copies of chloroplast genes can be readily identified across plants through sequence homology searches, taking advantage of the thousands of complete chloroplast genome sequences currently available for green plants. Third, comparative studies of convergent evolution in $\mathrm{C}_{4}$ photosynthesis are facilitated by detailed reconstruction of phylogenetic relationships within groups with both $\mathrm{C}_{4}$ and $\mathrm{C}_{3}$ lineages. Fourth, signatures of positive selection have been found in multiple chloroplast genes in taxa that contain both $\mathrm{C}_{3}$ and $\mathrm{C}_{4}$ plants, although only the genes $r b c L$ and $p s a J$, which encodes a small subunit of the Photosystem I complex, showed evidence of adaptive changes exclusively in $\mathrm{C}_{4}$ lineages (Christin, et al. 2008; Goolsby, et al. 2018; Piot, et al. 2018). Finally, most chloroplast genes occur as single copy loci, as opposed to the multiple paralogs typically present for plant genes encoded in the nucleus.

In this study, we analyzed 67 chloroplast genes from 64 grass species, including $43 \mathrm{C}_{4}$ and $19 \mathrm{C}_{3}$ species belonging to the PACMAD clade, named after six of its most representative subfamilies: Panicoideae, Arundinoideae, Chloridoideae, Micrairoideae, Aristidoideae and Danthonioideae. Using published information, we placed thirteen known independent $\mathrm{C}_{3}$ to $\mathrm{C}_{4}$ transitions in the reconstructed phylogeny of these 64 species. We applied a series of tests based on convergent vs. non-convergent amino acid replacements and determined that convergent molecular evolution occurred at a higher rate in chloroplast genes of $\mathrm{C}_{4}$ lineages compared to $\mathrm{C}_{3}$ lineages, a pattern that remained largely unchanged after excluding the RbcL protein from the convergence analyses. Our findings suggest that the evolutionary trajectories of multiple chloroplast genes have been affected during the emergence of the $\mathrm{C}_{4}$ adaptation in the PACMAD clade, a result that has significant implications for our understanding of $\mathrm{C}_{4}$ photosynthesis

\section{Methods}

\section{Data source and filtering}


We queried NCBI GenBank (Sayers, et al. 2019) for complete chloroplast genome sequences of grass species that were included in phylogenetic analyses by the Grass Phylogeny Working Group II (2012) and downloaded the corresponding coding sequences. Each species was assigned to either $\mathrm{C}_{3}$ or $\mathrm{C}_{4}$ type following the results of the Grass Phylogeny Working Group II (2012). Additionally, we downloaded the coding chloroplast sequences for Dichanthelium acuminatum, Thyridolepis xerophila, Sartidia dewinteri and Sartidia perrieri $\left(\mathrm{C}_{3}\right.$ species) (Brown and Smith 1972; Smith and Brown 1973; Hattersley and Stone 1986; Hattersley, et al. 1986; Besnard, et al. 2014). We used the standalone blastn ver. 2.2.29+ (Camacho, et al. 2009 ) with the Expect value (E) cutoff of $1 \mathrm{e}^{-10}$ to determine putative sequence orthology with coding sequences of the Zea mays chloroplast genes (Maier, et al. 1995). Single copy putative orthologs that were present in more than $95 \%$ of the species were retained for further analysis (Table S1).

\section{Multiple sequence alignment}

We aligned the individual sequences using TranslatorX ver. 1.1 (Abascal et al., 2010) and the multiple sequence aligner MUSCLE with default parameters. Alignments were further adjusted manually using BioEdit ver. 7.0.9.0 (Hall 1999). Stop codons and sites that could not be aligned unambiguously were removed.

\section{Phylogeny reconstruction}

We concatenated the individual sequence alignments and extracted third codon position sites for phylogeny reconstruction. We ran PartitionFinder ver. 1.1.1 (Lanfear, et al. 2012) to identify the best partitioning scheme (partitioning by gene) for the downstream analysis using both Akaike information criterion (AIC) (Akaike 1973) and Bayesian information criterion (BIC) (Schwarz, 1978). We then used maximum likelihood framework as implemented in RAxML ver. 8.2.10 (Stamatakis 2014) to reconstruct the phylogeny. Branch support was estimated using 1,000 bootstrap replicates. Oryza sativa and Brachypodium distachyon from the BOP (Bambusoideae, Oryzoideae and Pooideae) clade were used as outgroup, whereas all ingroup species belonged to the PACMAD clade. We used FigTree ver. 1.4.0 (Rambaut 2012) to rearrange and visualize the phylogeny, and the figures were edited further to improve readability and to indicate $\mathrm{C}_{4} / \mathrm{C}_{3}$ classification.

\section{Ancestral state reconstruction}

We reconstructed ancestral states at each phylogenetic node for each individual gene using the program codeml from the software package PAML ver. 4.9a (Yang 2007) and the basic codon substitution model (model $=0$, NSsites $=0$ ). The guide tree consisted of the cladogram of all species with available sequences for each individual gene. Sites with gaps in one or more PACMAD species were excluded.

\section{Definition and characteristics of "reference branches"}


In the reconstructed PACMAD phylogeny, we identified the branches including the most recent common ancestors of $\mathrm{C}_{4}$-only clades and $\mathrm{C}_{3}$-only clades. We refer to these branches as

248 " $\mathrm{C}_{4}$ reference branches" and "C $\mathrm{C}_{3}$ reference branches", respectively (see Figs. 1 and 2). We then

249 compared the inferred protein sequence of each reference branch with the inferred sequence in

250 their ancestral branch (next branch toward the root), in order to identify individual site changes

251 that occurred along reference branches.

252 To assess the number of convergent and non-convergent replacements, amino acid

253 changes were compared in all possible pairs of reference branches. Replacements in two

254 reference branches that resulted in the same state (amino acid) at a given site were considered

255 convergent, regardless of whether the corresponding ancestral states were the same or different

256 (Castoe, et al. 2009). After identifying convergent replacements, we separated them into parallel

257 and convergent changes (Zhang and Kumar 1997; Storz 2016). Likewise, two replacements were

258 considered non-convergent if states at the descendant orthologous sites were different, regardless

259 of the corresponding ancestral states (Castoe, et al. 2009).

260 The pairwise comparisons between reference branches are akin to the phylogenetically

261 independent contrast (PIC) method developed by Felsenstein (Felsenstein 1985). In the PIC

262 approach, the values to compare are represented by differences between branches. The

263 differences between two branches are independent of the differences between two other

264 branches. Therefore, pairwise comparisons of these values are independent and can be tested

265 using $2 \times 2$ contingency table tests (see also below). In our study, pairwise comparisons are

266 independent from each other, i.e., replacements in each pair of branches are independent of

267 replacements in each other pairs of branches. The difference from the PIC method is that we

268 compare both differences (non-convergent replacements) and similarities (convergent

269 replacements). A similar approach have been used in studies of convergent amino acid

270 replacements (Castoe, et al. 2009; Foote, et al. 2015; Thomas and Hahn 2015).

$271 \quad$ Reference branch lengths were extracted from the RAxML phylogeny obtained on the

272 AIC partitioning scheme (Fig. S2). Testing was performed on the sum of pairs of branch lengths

273 for each photosynthesis type using the R package exactRankTests (Table S2).

274

\section{Inference of convergent and non-convergent replacements and statistical testing}

Using the approach described above, we identified putative convergent and non-

278 within each of the three categories: (1) two $\mathrm{C}_{4}$ reference branches $\left(\mathrm{C}_{4}: \mathrm{C}_{4}\right),(2) \mathrm{C}_{3}$ reference

279 branch and $\mathrm{C}_{4}$ reference branch $\left(\mathrm{C}_{3}: \mathrm{C}_{4}\right)$, and $(3)$ two $\mathrm{C}_{3}$ reference branches $\left(\mathrm{C}_{3}: \mathrm{C}_{3}\right)$.

280 To test the significance of replacement differences between categories we used the

281 Boschloo's exact unconditional test (Boschloo 1970) implemented in the SciPy library ver. 1.7.1

282 in python3 (Virtanen, et al. 2020). In the Boschloo's test, the p-value from the Fisher's exact test

283 represents the test statistic of the exact unconditional test. It has been shown that Boschloo's test

284 is more powerful than Fisher's exact test (Mehrotra, et al. 2003). There is no restriction to using

285 contingency table tests, including Boschloo's test, on categories with different sample size, as 
286 long as the categories are independent (Mehrotra, et al. 2003), as in the case of reference

287 branches in our phylogeny.

288

Data availability

Raw data, including alignments, fasta sequences, and phylogenetic analyses data, are available through the following Figshare repository:

292 https://figshare.com/articles/dataset/Convergence-chlorplast-genes-C4-Casola-Li-

$2932021 / 15180690$.

\section{Results}

\section{Phylogeny reconstructions}

We examined 63 grass chloroplast genomes to identify gene orthologs for Zea mays chloroplast genes and extracted the corresponding coding and protein sequences. The resulting dataset included up to $67 \mathrm{DNA}$ /protein sequences in 64 grass species that were retained for further analysis (Table S1). One to four sequences were absent in thirteen species. Out of 64 species, 43 were classified as $\mathrm{C}_{4}$ and 21 (including two outroup species) as $\mathrm{C}_{3}$. The reconstructed phylogeny is well supported, except for three branches with low to moderate bootstrap values, and it is consistent for both AIC and BIC partitioning schemes (Fig. 1 and Figs. S1-S3). We identified thirteen $\mathrm{C}_{4}$ reference branches that represent putative $\mathrm{C}_{3}$ to $\mathrm{C}_{4}$ transitions, and nine $\mathrm{C}_{3}$ reference branches (Fig. 1). Four pairs of reference branches corresponding to $\mathrm{C}_{3}$ to $\mathrm{C}_{4}$ transitions-B-C, E-F, J-L and S-T-are sister to each other in Figure 1. Phylogenetic inferences from deep-taxonomic sampling of the PACMAD clade has shown that each of the these four pairs of reference branches is separated by at least one clade of $\mathrm{C}_{3}$ species (Grass Phylogeny Working Group 2012), supporting the independent origin of $\mathrm{C}_{4}$ photosynthesis in all reference branches shown in Figure 1. However, no high-quality chloroplast genomes are available for any of the $\mathrm{C}_{3}$ species between these pairs of reference $\mathrm{C}_{4}$ branches, precluding their inclusion in our study.

Overall, the reference branches A-V showed support values that were in close agreement with those reported in the Grass Phylogeny Working Group II (2012), including the three branches with low statistical support in our tree. Importantly, the species topology was identical between the two phylogenies downstream these three branches. We also noticed three other branches that shared higher statistical support in our phylogeny compared to the Grass Phylogeny Working Group II tree. Two of these branches occurred in the subtribe Boivinellinae and correspond to the split between the group $\mathrm{J} / \mathrm{K}$ and the branch $\mathrm{L}$, and the split between the group $\mathrm{I} / \mathrm{J} / \mathrm{K} / \mathrm{L}$ and the branch $\mathrm{M}$ (Fig. 1). The third node with higher support in our phylogeny correspond to the reference branch $\mathrm{Q}$ (tribe Arundoideae).

\section{Convergent and non-convergent amino acid replacements across chloroplast proteins}


We assessed the level of molecular convergence in $\mathrm{C}_{3}$ to $\mathrm{C}_{4}$ transitions by quantifying convergent and non-convergent amino acid replacements across the PACMAD phylogeny by performing pairwise comparisons of reconstructed sequences in reference branches (Figs. 2 and 3, Table S3; see Methods). A total of 217 sites showed at least one convergent replacement: 104 in $\mathrm{C}_{4}: \mathrm{C}_{4}, 120$ in $\mathrm{C}_{3}: \mathrm{C}_{4}$ and 34 in $\mathrm{C}_{3}: \mathrm{C}_{3}$ pairs. A further 201 sites exhibited one or more nonconvergent replacements: 96 in $\mathrm{C}_{4}: \mathrm{C}_{4}, 121$ in $\mathrm{C}_{3}: \mathrm{C}_{4}$, and 39 in $\mathrm{C}_{3}: \mathrm{C}_{3}$ pairs (Table 1). The difference in convergent/non-convergent site distributions between the three photosynthesis types was not statistically significant ( $P \geq 0.05$, Boschloo's test; Table 1$)$. The vast majority of convergent replacements shared the same ancestral state and should thus be considered parallel replacements according to widely accepted definitions of convergence (Zhang and Kumar 1997; Storz 2016). Only two sites, one in MatK (T205S/K205S in two $\mathrm{C}_{4}$ reference branches) and the other in $\mathrm{NdhF}$ (L636I/K636I in one $\mathrm{C}_{4}$ and three $\mathrm{C}_{3}$ reference branches), shared replacements with different ancestral states, representing true convergent sites (Table S3).

To control for possible biases in the counting of convergent replacements due to branch length variation, we tested whether reference branch lengths in the three photosynthesis types $\mathrm{C}_{4}: \mathrm{C}_{4}, \mathrm{C}_{3}: \mathrm{C}_{4}$ and $\mathrm{C}_{3}: \mathrm{C}_{3}$ were different (Table S2). We found no significant difference among types $(P>0.5$ for each of the three pairwise comparisons, Mann-Whitney $U$ test). We performed the same test only on branches with convergent and non-convergent replacements and found no significant difference between categories $(P>0.5$, Mann-Whitney $U$ test; Table S2). Therefore, branch length variation between the three types is not expected to affect our results.

Among the $\mathrm{C}_{4}$ reference branches, several individual sites showed high contrast in the number of branches involved in convergent and non-convergent replacements (Fig. 3, Tables S3 and S4). For example, seven $\mathrm{C}_{4}$ branches (54\%) shared the H18Q replacement in the product of $n d h H$, with no non-convergent replacements. Six, five, and four $\mathrm{C}_{4}$ branches $(46 \%, 38 \%$, and $31 \%$ ) showed convergent replacements at three sites in the RbcL protein (V101I, M309I, and A328S, respectively). Furthermore, six $\mathrm{C}_{4}$ branches shared the $\mathrm{S} 25 \mathrm{G}$ replacement in the product of $n d h I$ and four L204F changes in the protein encoded by matK. In all these cases, there were no other convergent or non-convergent replacements in $\mathrm{C}_{3}: \mathrm{C}_{3}$ or $\mathrm{C}_{3}: \mathrm{C}_{4}$ branch comparisons, except for one $\mathrm{H} 18 \mathrm{Q}$ change in $\mathrm{NdhH}$ in $\mathrm{a}_{3}: \mathrm{C}_{3}$ branch. Two sites with convergent replacements in the proteins encoded by $n d h F(\mathrm{~L} 557 \mathrm{~F})$ and $r p o C 2(\mathrm{H} 875 \mathrm{Y})$ were found uniquely in $\mathrm{C}_{3}: \mathrm{C}_{3}$ pairs, and only one site in the protein Rps3 showed convergence independently in $\mathrm{C}_{4}: \mathrm{C}_{4}$ and $\mathrm{C}_{3}: \mathrm{C}_{3}$ pairs (Fig. 3).

We then searched for convergent replacements that occurred along more than two $\mathrm{C}_{4}$ branches at sites that remained otherwise conserved in $\mathrm{C}_{3}$ and $\mathrm{C}_{4}$ lineages, arguing that such changes could result from selective pressure rather than drift. We identified twelve $\mathrm{C}_{4}$-specific convergent sites in proteins from 7 genes: matK, $n d h F, n d h G, n d h I, r b c L, r p o C 1$ and $r p o C 2$ (Table S4). Five of these sites were found in RbcL, whereas two sites were identified in NdhI. We also observed two convergent sites $\mathrm{NdhF}$ and one in RpoC2 that were uniquely found in three $\mathrm{C}_{3}$ branches. 


\section{Molecular convergence in individual chloroplast proteins}

Convergent and non-convergent amino acid replacements were detected in the products of 45 chloroplast genes, thirteen of which had at least one site with four or more replacements (Fig. 4, Table 1 and Table S3). Twenty-four genes had convergent changes in $\mathrm{C}_{4}: \mathrm{C}_{4}, 26$ in $\mathrm{C}_{3}: \mathrm{C}_{4}$, and 13 in $\mathrm{C}_{3}: \mathrm{C}_{3}$ types of pairs (Table 1). Although the convergent/ non-convergent replacement ratio was higher in $\mathrm{C}_{4}: \mathrm{C}_{4}$ pairs than $\mathrm{C}_{3}: \mathrm{C}_{4}$ and $\mathrm{C}_{3}: \mathrm{C}_{3}$ pairs, the differences between the three photosynthesis types were not statistically significant $(P \geq 0.05$, Boschloo's test; Table 1$)$. The lack of replacements was the single most common state for chloroplast proteins across photosynthesis types; however, in $\mathrm{C}_{4}: \mathrm{C}_{4}$ there were more genes with a higher number of convergent vs. non-convergent replacements (Fig. 4 and Table S5).

Overall, 26 proteins showed a higher number of convergent vs. non-convergent sites, of which 16, 13 and 10 were found in $\mathrm{C}_{4}: \mathrm{C}_{4}, \mathrm{C}_{3}: \mathrm{C}_{4}$ and $\mathrm{C}_{3}: \mathrm{C}_{3}$ pairs, respectively (Fig. 5 and Table $\mathrm{S} 5)$. We found statistically significant differences in the number of convergent vs. nonconvergent replacements between $\mathrm{C}_{4}: \mathrm{C}_{4}$ and $\mathrm{C}_{3}: \mathrm{C}_{4}$ pairs, but not $\mathrm{C}_{3}: \mathrm{C}_{3}$ pairs, in the products of the genes $r b c L$, rpoC1 and rpoC2 $(P<0.05$, Boschloo's test; Table S5). In RbcL and RpoC1, $\mathrm{C}_{4}: \mathrm{C}_{4}$ pairs shared much higher proportion of convergent vs. non-convergent replacements, whereas the opposite was true in $\mathrm{RpoC} 2$. RpoC1 was also the only protein showing more convergent than non-convergent replacements in $\mathrm{C}_{4}: \mathrm{C}_{4}$ pairs compared to $\mathrm{C}_{3}: \mathrm{C}_{3}$ and $\mathrm{C}_{3}: \mathrm{C}_{4}$ pairs. In $\mathrm{C}_{4}: \mathrm{C}_{4}$ pairs, $\mathrm{RpoC} 1$ shared 4 convergent and 1 non-convergent replacement, compared to 1 and 2 in $\mathrm{C}_{3}: \mathrm{C}_{3}$ pairs and 1 and 5 in $\mathrm{C}_{3}: \mathrm{C}_{4}$ pairs, respectively. Additionally, the proteins $\mathrm{NdhG}$, NdhI, PsaI, RpoA, Rps4 and Rps11 exhibited convergent replacements only in $\mathrm{C}_{4}: \mathrm{C}_{4}$ pairs (Table S5). When considering the number of affected sites rather than the number of replacements, no genes showed a significantly different pattern between photosynthesis types $(P$ $\geq 0.05$, Boschloo's test; Table S5).

The proteins encoded by matK, rpoC2 and $n d h F$ shared much higher numbers of both convergent and non-convergent replacements than other chloroplast proteins across all photosynthesis type comparisons (Table S5). Both $m a t K$ and $n d h F$ are known to be rapidly evolving and have been consistently used in low taxonomic level phylogenetic studies in flowering plants (Patterson and Givnish 2002; Barthet and Hilu 2008). The gene rpoC2 has also been recently described as a useful phylogenetic marker in angiosperms (Walker, et al. 2019).

\section{Molecular convergence across reference branches}

The comparison of reference branch pairs with convergent and non-convergent replacements revealed remarkable differences between photosynthesis types. Overall, $\mathrm{C}_{4}: \mathrm{C}_{4}$ pairs of reference branches showed a distribution skewed toward more convergent and non-convergent 
406 replacements than the two other categories (Fig. 6). There were significantly fewer pairs of $\mathrm{C}_{4}: \mathrm{C}_{4}$ 407 reference branches with no replacements and with no convergent replacements than $\mathrm{C}_{3}: \mathrm{C}_{4}$ and $408 \mathrm{C}_{3}: \mathrm{C}_{3}$ pairs $(P<0.05$, Boschloo's test; Table 2$)$. Conversely, significantly more $\mathrm{C}_{4}: \mathrm{C}_{4}$ pairs 409 shared more convergent than non-convergent replacements, and at least two convergent changes 410 compared to $\mathrm{C}_{3}: \mathrm{C}_{4}$ and $\mathrm{C}_{3}: \mathrm{C}_{3}$ pairs $(P<0.05$, Boschloo's test; Table 2$)$. No significant difference 411 was observed between pairs of $\mathrm{C}_{3}: \mathrm{C}_{4}$ and pairs of $\mathrm{C}_{3}: \mathrm{C}_{3}$. We found identical patterns when the 412 same analyses were performed after excluding all replacements in the RbcL protein, except for 413 the lack of a significant difference between $\mathrm{C}_{4}: \mathrm{C}_{4}$ and $\mathrm{C}_{3}: \mathrm{C}_{3}$ in the proportion of pairs with non414 convergent replacements and pairs with more convergent than non-convergent changes (Table 415 S6).

\section{Distribution of amino acid replacements across PACMAD lineages}

418 Convergent and non-convergent replacements were preferentially found in specific pairs of reference branches. In $\mathrm{C}_{4}$ pairs, convergent sites were most abundant between Danthoniopsis dinteri and Aristida purpurea (ten sites, branches $\mathrm{P}$ and V in Fig. 1), whereas non-convergent sites were most common between Centropodia glauca and Aristida purpurea (ten sites, branches $\mathrm{S}$ and $\mathrm{V}$ in Fig. 1). In pairwise $\mathrm{C}_{3}$ branch comparisons, most convergent sites were identified between both Zeugites pittieri and Danthonieae (branches $\mathrm{N}$ and $\mathrm{R}$ in Fig. 1) and Danthonieae and Sartidia spp. (branches R and U in Fig. 1), whereas the most non-convergent site-rich pair was formed by Zeugites pittieri and Sartidia spp. (eight sites, branches $\mathrm{N}$ and U in Fig. 1; Table S7).

\section{Molecular convergence in the RuBisCO large subunit}

We further inspected the evolution of the RuBisCO large subunit across the PACMAD clade. A total of 4 out of $9 \mathrm{RbcL}$ amino acids with convergent changes in $\mathrm{C}_{4}$ reference branches_V101I, A281S, M309I and A328S — have been identified in previous studies on PACMAD grasses (Christin, et al. 2008; Piot, et al. 2018) as sites that experienced adaptive evolution in $\mathrm{C}_{4}$ species (Table 3). A further site, T143A, was found to evolve under positive selection in $\mathrm{C}_{3}$ to $\mathrm{C}_{4}$ transitions in monocots (Studer, et al. 2014). Interestingly, an adaptive S143A replacement has also been detected in the gymnosperm Podocarpus (Sen, et al. 2011). Three more sites with convergent replacements — at positions 93, 94 and 461 — correspond to amino acids that were reported to evolve under positive selection in different groups of seed plants by Kapralov and Filatov (2007). Thus, all of the $r b c L$ codons that appear to have evolved convergently among the PACMAD $\mathrm{C}_{4}$ lineages we have examined are also known to have experienced adaptive evolution in seed plants, but not all of them have been shown to evolve adaptively in $\mathrm{C}_{4}$ grasses.

\section{Discussion}


445

446

447

448

449

450

451

452

453

454

455

456

457

458

459

460

461

462

463

464

465

466

467

468

469

470

471

472

473

474

475

476

477

478

479

480

481

482

483

484

The recurrent emergence of carbon-concentration mechanisms (CCMs) across multiple angiosperm clades in the past 35 million years represents one of the most striking examples of convergent evolution of a complex phenotypic trait (Sage, et al. 2011; Heyduk, et al. 2019).

Several investigations have shown that the phenotypic parallelism across $\mathrm{C}_{4}$ lineages is to some extent mirrored by convergent changes in the sequence of proteins with key metabolic roles in the biochemistry of $\mathrm{C}_{4}$ photosynthesis, both in monocots and eudicots (Christin, et al. 2007; Besnard, et al. 2009; Christin, Petitpierre, et al. 2009; Christin, Samaritani, et al. 2009; Kapralov, et al. 2011; Goolsby, et al. 2018). Furthermore, biochemical analyses have determined that some of these changes reflect adaptive shifts, as in the case of the increased availability of $\mathrm{CO}_{2}$ at the RuBisCO site (Studer, et al. 2014). Substantial changes in several RuBisCO kinetic traits associated to $C_{3}$ to $C_{4}$ transitions have recently been described (Bouvier, et al. 2021). Further evidence of changes in the selective pressure associated to the $\mathrm{C}_{3}$ to $\mathrm{C}_{4}$ transitions have emerged from the detection of several positively selected sites in multiple genes associated with photosynthetic processes (Christin, et al. 2008; Studer, et al. 2014; Goolsby, et al. 2018; Piot, et al. 2018). These and other discoveries have paved the way to a more nuanced understanding of the molecular basis of phenotypic convergence in CCM plants and may accelerate the development of crop varieties with augmented resistance to high temperature and low water availability.

For these aims to be fully realized, a robust framework to assess the extent and phenotypic impact of convergent molecular changes is necessary. Along the lines of strategies applied in vertebrates research (Castoe, et al. 2009; Foote, et al. 2015; Thomas and Hahn 2015; Zou and Zhang 2015), we presented here the results of a novel methodological approach to the study of molecular convergence in $\mathrm{C}_{4}$ grasses. We investigated patterns of convergent and nonconvergent amino acid changes in nearly 70 chloroplast proteins across multiple $\mathrm{C}_{4}$ and $\mathrm{C}_{3}$ lineages in the PACMAD clade, with the goal of testing a specific hypothesis: is the evolution of chloroplast proteins showing stronger signatures of convergent amino acid replacements in $\mathrm{C}_{4}$ lineages compared to $\mathrm{C}_{3}$ lineages? This analysis also allowed us to establish if proteins other than enzymes involved in the CCM biochemistry underwent parallel amino acid changes in $\mathrm{C}_{4}$ lineages. Our reasoning is that many proteins expressed in the chloroplast could have experienced similar selective pressure across multiple $\mathrm{C}_{3}$ to $\mathrm{C}_{4}$ transitions and might have accumulated convergence replacements as a result. In agreement with our expectation, dozens of nuclear genes sharing signatures of positive or relaxed selection and likely associated with the evolution of $\mathrm{C}_{4}$ PACMAD grasses have been recently described, albeit these analyses relied on a limited number of species (Huang, et al. 2017).

We based our analysis on the identification of amino acid replacements shared by pairs of reference $\mathrm{C}_{4}$ branches, defined here as branches corresponding to $\mathrm{C}_{3}$ to $\mathrm{C}_{4}$ transitions in the PACMAD phylogeny. We compared these changes to those identified in reference $\mathrm{C}_{3}$ branches, namely all $\mathrm{C}_{3}$ lineages that include only $\mathrm{C}_{3}$ species (Figs. 1 and 2), and to changes found between 
485 reference $\mathrm{C}_{3}$ and $\mathrm{C}_{4}$ branches. For each of the three possible pairs of photosynthesis types, $\mathrm{C}_{4}: \mathrm{C}_{4}$, $486 \mathrm{C}_{3}: \mathrm{C}_{4}$ and $\mathrm{C}_{3}: \mathrm{C}_{3}$, we determined the number of amino acid sites, genes and pairs of reference 487 branches with convergent replacements.

488 We detected signatures of convergent evolution in all types of datasets. First, we 489 identified many individual replacements that emerged repeatedly and uniquely in $\mathrm{C}_{4}$ reference 490 branches, particularly in the proteins RbcL, NdhH, NdhI and MatK. We also observed $\mathrm{C}_{3}$ 491 specific convergent replacements in $\mathrm{NdhF}$ and RpoC2, and a case of multiple $\mathrm{C}_{4}$ and $\mathrm{C}_{3}$ 492 convergent changes in Rps3. Additionally, we identified 7 chloroplast genes with one or more $493 \mathrm{C}_{4}$-specific convergent sites and 3 chloroplast genes with at least one $\mathrm{C}_{3}$-specific convergent site.

494 Second, we found evidence of significantly higher rates of convergent replacements in $\mathrm{C}_{4}$

495 lineages in both $\mathrm{RbcL}$ and $\mathrm{RpoC} 1$, and several convergent replacements that occurred 496 exclusively in $\mathrm{C}_{4}: \mathrm{C}_{4}$ pairs in proteins encoded by $n d h G, n d h I, p s a I, r p o A, r p s 4$ and $r p s 11$. These genes are involved in a variety of biological processes in the chloroplast, from the cyclic electron transport in ( $n d h G$ and $n d h I)$ and the stabilization of ( $p s a I)$ the photosystem I, to transcription (rpoA and rpoC1), translation (rps4 and rps11) and $\mathrm{CO}_{2}$ fixation $(r b c L)$. Third, we identified statistically significant differences in pairs of $\mathrm{C}_{4}$ branches with convergent replacements (Table 2). Crucially, we observed more pairs with higher convergent than non-convergent replacements in $\mathrm{C}_{4}: \mathrm{C}_{4}$ compared to both $\mathrm{C}_{3}: \mathrm{C}_{3}$ and $\mathrm{C}_{3}: \mathrm{C}_{4}$, even after removing replacements identified in the $\mathrm{RuBisCO}$ large subunit, RbcL.

Altogether, these findings suggest that multiple biochemical processes occurring in the chloroplast might have experienced recurrent adaptive changes associated with the emergence of $\mathrm{C}_{4}$ photosynthesis. Notably, some of these proteins are not directly involved in the lightdependent or light-independent reactions of the photosynthesis, implying that processes such as regulation of gene expression and protein synthesis in the chloroplast are also experiencing significant selective pressures during the transition from $\mathrm{C}_{3}$ to $\mathrm{C}_{4}$ plants. These results should motivate further studies to determine the prevalence of convergent amino acid replacements in transitions to CCMs among the thousands of proteins encoded by nuclear genes but expressed in the chloroplast (Jarvis and Lopez-Juez 2013). Although such analyses are currently hindered by the limited number of sequenced nuclear genomes in taxa with multiple $\mathrm{C}_{3}$ and $\mathrm{C}_{4}$ lineages, including the PACMAD clade, genome-wide investigations of convergent replacements will be possible in the near future given the current pace of DNA sequencing in plants.

A further important conclusion drawn from these results is that convergent replacements are not uncommon between $\mathrm{C}_{3}: \mathrm{C}_{3}$ and $\mathrm{C}_{3}: \mathrm{C}_{4}$ lineages. This is possibly due to some environmental factors affecting the evolution of chloroplast genes that are shared across grass lineages regardless of their photosynthesis type.

524 highlighted novel potentially adaptive changes among PACMAD species. Importantly, these 
525

novel convergent replacements are known to evolve under positive selection in non-PACMAD seed plants (Kapralov and Filatov 2007; Sen, et al. 2011). This underscores the potential of our approach to identify novel changes with functional significance in the transition to CCMs in grasses, as opposed to standard statistical tests of positive selection. Alternatively, some RbcL sites could experience convergence across a variety of seed plants because of selective pressure other than those associated with $\mathrm{C}_{3}$ to $\mathrm{C}_{4}$ transitions.

Overall, our results are robust to several possible confounding factors. First, we analyzed branches that are strongly supported in our phylogeny reconstruction. The phylogenetic tree built using the 67 chloroplast genes is well supported, with the exception of three branches with fairly low bootstrap support. However, all three branches are short and have minimal impact upon our conclusions regarding $\mathrm{C}_{4}$ evolution (Fig. 1 and Figs. S1-S3). Moreover, the tree is largely consistent with a comprehensive recent study of 250 grasses based on complete plastome data (Saarela, et al. 2018). Second, by focusing only on reference branches and ignoring amino acid replacements that may have occurred after the divergence of species within a given $\mathrm{C}_{4}$ clade, our strategy provided a conservative estimate of the number of convergent changes that could have occurred during the evolution of PACMAD grasses. Third, we eliminated genes with possible paralogous copies, which could have introduced false positive replacements.

We recognize some potential caveats in our approach. By relying on a relatively small sample of PACMAD species, our statistical power to detect signatures of convergent evolution was limited. Increasing the number of reference $\mathrm{C}_{4}$ and $\mathrm{C}_{3}$ lineages should provide a broader representation of convergent replacements in $\mathrm{C}_{4}$ clades. Furthermore, we applied a strict definition of convergence that ignores changes to amino acids with similar chemical properties. We think that a conservative approach was necessary given that amino acids with similar chemical properties might have a very different functional effect on protein activity given their size and tridimensional interactions with nearby residues. Third, we assumed that all the observed convergent replacements were the result of convergent phenotypic changes, which fall under the general category of homoplasy (Avise and Robinson 2008). However, some of these replacements could instead represent hemiplasy, or character state changes due to introgression between different $\mathrm{C}_{4}$ lineages, incomplete lineage sorting (ILS) of reference alleles or horizontal gene transfer (Avise and Robinson 2008). Recombination between chloroplast genomes, which is required for introgression to occur, has been documented but appears to be rare (CarbonellCaballero, et al. 2015; Greiner, et al. 2015; Sancho, et al. 2018). Introgression or horizontal gene transfer between congeneric species has been associated to the acquisition of part of the $\mathrm{C}_{4}$ biochemical pathway in the PACMAD genus Alloteropsis (Christin, et al. 2012; Olofsson, et al. 2016). However, these transfers were limited to a few nuclear genes. Moreover, only a very few cases of horizontal transfer between chloroplast genomes have been reported in plants (Stegemann, et al. 2012). Therefore, the contribution of hemiplasy to the observed pattern of convergent replacements in $\mathrm{C}_{4}$ lineages is likely to be minimal. Finally, we treated $\mathrm{C}_{4}$ species 
565 regardless of their photosynthesis subtype (NAPD-ME, NAD-ME and PEPCK), which is known

566 to vary among PACMAD subfamilies (Taylor, et al. 2010). We argue that our results are

567 conservative with regard to this aspect because convergent replacements should be expected to

568 occur more often between $\mathrm{C}_{4}$ groups sharing the same photosynthesis subtype.

\section{Conclusions}

In this study, we showed that molecular convergent evolution in the form of recurrent amino acid replacements affected multiple chloroplast proteins in $\mathrm{C}_{4}$ lineages of the PACMAD clade of grasses. This finding significantly broadened the number of genes known to have evolved convergently in $\mathrm{C}_{4}$ species. We observed for the first time that genes not directly involved in photosynthesis-related processes experienced convergent changes, suggesting that future efforts should rely whenever possible on genome-wide analyses of amino acid changes rather than focus primarily on candidate key metabolic genes, similarly to previous investigations on gene expression patterns in $\mathrm{C}_{4}$ and CAM plants. Our methodological approach based on the comparison of convergent and non-convergent replacements among photosynthesis types underscores the importance of a more rigorous hypothesis-based testing of convergent evolution signatures in $\mathrm{C}_{4}$ plant evolution. Our results should inform more nuanced approaches to introduce $\mathrm{CCM}$-like processes in $\mathrm{C}_{3}$ crops.

\section{Acknowledgements}

We thank two reviewers for comments and suggestions that have led to a significant improved version of this manuscript, and to A. Michelle Lawing for comments on the manuscript. This project was supported by the National Institute of Food and Agriculture, U.S. Department of Agriculture, under award number TEX0-1-9599, the Texas A\&M AgriLife Research, and the Texas A\&M Forest Service.

604123. 
605 Besnard G, Christin PA, Male PJ, Lhuillier E, Lauzeral C, Coissac E, Vorontsova MS. 2014.

606 From museums to genomics: old herbarium specimens shed light on a C3 to C4 transition. J Exp 607 Bot 65:6711-6721.

608 Besnard G, Muasya AM, Russier F, Roalson EH, Salamin N, Christin PA. 2009. Phylogenomics 609 of C(4) photosynthesis in sedges (Cyperaceae): multiple appearances and genetic convergence.

610 Mol Biol Evol 26:1909-1919.

611 Boschloo RD. 1970. Raised conditional level of significance for the $2 \times 2$-table when testing the 612 equality of two probabilities. Stat Neerl 24:1-9.

613 Bouvier JW, Emms DM, Rhodes T, Bolton JS, Brasnett A, Eddershaw A, Nielsen JR, Unitt A, 614 Whitney SM, Kelly S. 2021. Rubisco Adaptation Is More Limited by Phylogenetic Constraint

615 Than by Catalytic Trade-off. Molecular Biology and Evolution 38:2880-2896.

616 Brown WV, Smith BN. 1972. Grass evolution, the Kranz syndrome, 13C/12C ratios, and

617 continental drift. Nature 239:345-346.

618 Camacho C, Coulouris G, Avagyan V, Ma N, Papadopoulos J, Bealer K, Madden TL. 2009.

619 BLAST+: architecture and applications. BMC Bioinformatics 10:421.

620 Carbonell-Caballero J, Alonso R, Ibanez V, Terol J, Talon M, Dopazo J. 2015. A Phylogenetic

621 Analysis of 34 Chloroplast Genomes Elucidates the Relationships between Wild and Domestic

622 Species within the Genus Citrus. Molecular Biology and Evolution 32:2015-2035.

623 Castoe TA, de Koning AP, Kim HM, Gu W, Noonan BP, Naylor G, Jiang ZJ, Parkinson CL,

624 Pollock DD. 2009. Evidence for an ancient adaptive episode of convergent molecular evolution.

625 Proc Natl Acad Sci U S A 106:8986-8991.

626 Christin PA, Arakaki M, Osborne CP, Edwards EJ. 2015. Genetic enablers underlying the

627

628

629

630 clustered evolutionary origins of C4 photosynthesis in angiosperms. Mol Biol Evol 32:846-858. Christin PA, Boxall SF, Gregory R, Edwards EJ, Hartwell J, Osborne CP. 2013. Parallel recruitment of multiple genes into c4 photosynthesis. Genome Biol Evol 5:2174-2187. Christin PA, Edwards EJ, Besnard G, Boxall SF, Gregory R, Kellogg EA, Hartwell J, Osborne CP. 2012. Adaptive evolution of C(4) photosynthesis through recurrent lateral gene transfer. Curr Biol 22:445-449.

Christin PA, Osborne CP, Chatelet DS, Columbus JT, Besnard G, Hodkinson TR, Garrison LM, Vorontsova MS, Edwards EJ. 2013. Anatomical enablers and the evolution of C4 photosynthesis in grasses. Proc Natl Acad Sci U S A 110:1381-1386.

Christin PA, Petitpierre B, Salamin N, Buchi L, Besnard G. 2009. Evolution of C-4 Phosphoenolpyruvate Carboxykinase in Grasses, from Genotype to Phenotype. Molecular Biology and Evolution 26:357-365.

Christin PA, Salamin N, Muasya AM, Roalson EH, Russier F, Besnard G. 2008. Evolutionary switch and genetic convergence on rbcL following the evolution of C4 photosynthesis. Mol Biol Evol 25:2361-2368.

Christin PA, Salamin N, Savolainen V, Duvall MR, Besnard G. 2007. C4 Photosynthesis evolved in grasses via parallel adaptive genetic changes. Curr Biol 17:1241-1247.

Christin PA, Samaritani E, Petitpierre B, Salamin N, Besnard G. 2009. Evolutionary insights on $\mathrm{C} 4$ photosynthetic subtypes in grasses from genomics and phylogenetics. Genome Biol Evol 1:221-230.

Felsenstein J. 1985. Phylogenies and the Comparative Method. American Naturalist 125:1-15. Foote AD, Liu Y, Thomas GW, Vinar T, Alfoldi J, Deng J, Dugan S, van Elk CE, Hunter ME, Joshi V, et al. 2015. Convergent evolution of the genomes of marine mammals. Nat Genet 47:272-275. 
651 Goolsby EW, Moore AJ, Hancock LP, De Vos JM, Edwards EJ. 2018. Molecular evolution of

652 key metabolic genes during transitions to C4 and CAM photosynthesis. Am J Bot 105:602-613.

653 Grass Phylogeny Working Group I. 2012. New grass phylogeny resolves deep evolutionary

654 relationships and discovers C4 origins. New Phytol 193:304-312.

655 Greiner S, Sobanski J, Bock R. 2015. Why are most organelle genomes transmitted maternally?

656 Bioessays 37:80-94.

657 Hall TA. 1999. BioEdit: a user-friendly biological sequence alignment editor and analysis

658 program for Windows 95/98/NT. Nucl Acids Symp Series 41:95-98.

659 Hattersley PW, Stone NE. 1986. Photosynthetic Enzyme-Activities in the C-3-C-4 Intermediate

660 Neurachne-Minor Blake,S.T. (Poaceae). Australian Journal of Plant Physiology 13:399-408.

661 Hattersley PW, Wong SC, Perry S, Roksandic Z. 1986. Comparative Ultrastructure and Gas-

662 Exchange Characteristics of the C3-C4 Intermediate Neurachne-Minor Blake,S.T. (Poaceae).

663 Plant Cell and Environment 9:217-233.

664 Heckmann D, Schulze S, Denton A, Gowik U, Westhoff P, Weber APM, Lercher MJ. 2013.

665 Predicting C-4 Photosynthesis Evolution: Modular, Individually Adaptive Steps on a Mount Fuji

666 Fitness Landscape. Cell 153:1579-1588.

667 Heyduk K, Moreno-Villena JJ, Gilman IS, Christin PA, Edwards EJ. 2019. The genetics of

668 convergent evolution: insights from plant photosynthesis. Nat Rev Genet.

669 Huang P, Studer AJ, Schnable JC, Kellogg EA, Brutnell TP. 2017. Cross species selection scans

670 identify components of C4 photosynthesis in the grasses. J Exp Bot 68:127-135.

671 Jarvis P, Lopez-Juez E. 2013. Biogenesis and homeostasis of chloroplasts and other plastids. Nat

672 Rev Mol Cell Biol 14:787-802.

673 Kapralov MV, Filatov DA. 2007. Widespread positive selection in the photosynthetic Rubisco

674 enzyme. BMC Evol Biol 7:73.

675 Kapralov MV, Kubien DS, Andersson I, Filatov DA. 2011. Changes in Rubisco kinetics during

676 the evolution of $\mathrm{C} 4$ photosynthesis in Flaveria (Asteraceae) are associated with positive selection

677 on genes encoding the enzyme. Mol Biol Evol 28:1491-1503.

678 Kapralov MV, Smith JA, Filatov DA. 2012. Rubisco evolution in C(4) eudicots: an analysis of

679 Amaranthaceae sensu lato. PLoS One 7:e52974.

680 Kellogg EA. 1999. Phylogenetic Aspects of the Evolution of C4 Photosynthesis. In: Sage RF,

681 Monson RK, editors. C4 Plant Biology. San Diego, California, USA: Academic Press. p. 411-

682444.

683 Knapp AK, Medina E. 1999. Lessons from Communities Dominated by C4 Plants. In: Sage RF,

684 Monson RK, editors. C4 Plant Biology. San Diego, California, USA: Academic Press. p. 251-

685283.

686 Lanfear R, Calcott B, Ho SY, Guindon S. 2012. Partitionfinder: combined selection of

687 partitioning schemes and substitution models for phylogenetic analyses. Mol Biol Evol 29:1695-

6881701.

689 Li B, Forster C, Robert CAM, Zust T, Hu L, Machado RAR, Berset JD, Handrick V, Knauer T,

690 Hensel G, et al. 2018. Convergent evolution of a metabolic switch between aphid and caterpillar

691 resistance in cereals. Science Advances 4.

692 Long SP. 1999. Environmental Responses. In: Sage RF, K. MR, editors. C4 Plant Biology. San

693 Diego, California, USA: Academic Press. p. 215-249.

694 Lu PT, Yu S, Zhu N, Chen YR, Zhou BY, Pan Y, Tzeng D, Fabi JP, Argyris J, Garcia-Mas J, et

695 al. 2018. Genome encode analyses reveal the basis of convergent evolution of fleshy fruit

696 ripening. Nature Plants 4:784-791. 
697 Maier RM, Neckermann K, Igloi GL, Kossel H. 1995. Complete Sequence of the Maize

698 Chloroplast Genome - Gene Content, Hotspots of Divergence and Fine-Tuning of Genetic

699 Information by Transcript Editing. Journal of Molecular Biology 251:614-628.

700 Maurino VG, Peterhansel C. 2010. Photorespiration: current status and approaches for metabolic

701 engineering. Curr Opin Plant Biol 13:249-256.

702 Mehrotra DV, Chan ISF, Berger RL. 2003. A cautionary note on exact unconditional inference

703 for a difference between two independent binomial proportions. Biometrics 59:441-450.

704 Natarajan C, Hoffmann FG, Weber RE, Fago A, Witt CC, Storz JF. 2016. Predictable

705 convergence in hemoglobin function has unpredictable molecular underpinnings. Science

$706 \quad 354: 336-339$.

707 Olofsson JK, Bianconi M, Besnard G, Dunning LT, Lundgren MR, Holota H, Vorontsova MS,

708 Hidalgo O, Leitch IJ, Nosil P, et al. 2016. Genome biogeography reveals the intraspecific spread

709 of adaptive mutations for a complex trait. Mol Ecol 25:6107-6123.

710 Parker J, Tsagkogeorga G, Cotton JA, Liu Y, Provero P, Stupka E, Rossiter SJ. 2013. Genome-

711 wide signatures of convergent evolution in echolocating mammals. Nature 502:228-231.

712 Patterson TB, Givnish TJ. 2002. Phylogeny, concerted convergence, and phylogenetic niche

713 conservatism in the core Liliales: insights from rbcL and ndhF sequence data. Evolution 56:233-

714252.

715 Piot A, Hackel J, Christin PA, Besnard G. 2018. One-third of the plastid genes evolved under positive selection in PACMAD grasses. Planta 247:255-266.

Preite V, Sailer C, Syllwasschy L, Bray S, Ahmadi H, Kramer U, Yant L. 2019. Convergent evolution in Arabidopsis halleri and Arabidopsis arenosa on calamine metalliferous soils.

Philosophical Transactions of the Royal Society B-Biological Sciences 374.

FigTree. Tree Figure Drawing Tool, version 1.4.0 [Internet]. 2012. Available from:

http://tree.bio.ed.ac.uk/software/figtree/

Saarela JM, Burke SV, Wysocki WP, Barrett MD, Clark LG, Craine JM, Peterson PM, Soreng RJ, Vorontsova MS, Duvall MR. 2018. A 250 plastome phylogeny of the grass family (Poaceae): topological support under different data partitions. PeerJ 6:e4299.

Sage RF. 2004. The evolution of C4 photosynthesis. New Phytol 161:341-370.

Sage RF. 1999. Why C4 Photosynthesis? In: Sage RF, Monson RK, editors. C4 Plant Biology.

San Diego, California, USA: Academic Press. p. 3-16.

Sage RF, Christin PA, Edwards EJ. 2011. The C(4) plant lineages of planet Earth. J Exp Bot 62:3155-3169.

Sage RF, Sage TL, Kocacinar F. 2012. Photorespiration and the evolution of C4 photosynthesis. Annu Rev Plant Biol 63:19-47.

732 Sancho R, Cantalapiedra CP, Lopez-Alvarez D, Gordon SP, Vogel JP, Catalan P, Contreras-

733 Moreira B. 2018. Comparative plastome genomics and phylogenomics of Brachypodium: flowering time signatures, introgression and recombination in recently diverged ecotypes. New Phytol 218:1631-1644.

Sayers EW, Cavanaugh M, Clark K, Ostell J, Pruitt KD, Karsch-Mizrachi I. 2019. GenBank. Nucleic Acids Res 47:D94-D99.

Sen L, Fares MA, Liang B, Gao L, Wang B, Wang T, Su YJ. 2011. Molecular evolution of rbcL in three gymnosperm families: identifying adaptive and coevolutionary patterns. Biol Direct 6:29.

Smith BN, Brown WV. 1973. The Kranz syndrome in the Gramineae as indicated by carbon isotopic ratios. Amer J Bot 60:505-513. 
743 Stamatakis A. 2014. RAxML version 8: a tool for phylogenetic analysis and post-analysis of 744 large phylogenies. Bioinformatics 30:1312-1313.

745 Stegemann S, Keuthe M, Greiner S, Bock R. 2012. Horizontal transfer of chloroplast genomes

746 between plant species. Proceedings of the National Academy of Sciences of the United States of

747 America 109:2434-2438.

748 Storz JF. 2016. Causes of molecular convergence and parallelism in protein evolution. Nature

749 Reviews Genetics 17:239-250.

750 Studer RA, Christin PA, Williams MA, Orengo CA. 2014. Stability-activity tradeoffs constrain

751 the adaptive evolution of RubisCO. Proc Natl Acad Sci U S A 111:2223-2228.

752 Taylor SH, Hulme SP, Rees M, Ripley BS, Woodward FI, Osborne CP. 2010. Ecophysiological

753 traits in C3 and C4 grasses: a phylogenetically controlled screening experiment. New Phytol

754 185:780-791.

755 Thomas GW, Hahn MW. 2015. Determining the Null Model for Detecting Adaptive

756 Convergence from Genomic Data: A Case Study using Echolocating Mammals. Mol Biol Evol

757 32:1232-1236.

758 Virtanen P, Gommers R, Oliphant TE, Haberland M, Reddy T, Cournapeau D, Burovski E,

759 Peterson P, Weckesser W, Bright J, et al. 2020. SciPy 1.0: fundamental algorithms for scientific

760 computing in Python. Nat Methods 17:261-272.

761 Walker JF, Walker-Hale N, Vargas OM, Larson DA, Stull GW. 2019. Characterizing gene tree

762 conflict in plastome-inferred phylogenies. PeerJ 7:e7747.

763 Williams BP, Johnston IG, Covshoff S, Hibberd JM. 2013. Phenotypic landscape inference

764 reveals multiple evolutionary paths to C4 photosynthesis. Elife 2:e00961.

765 Yang Z. 2007. PAML 4: phylogenetic analysis by maximum likelihood. Mol Biol Evol 24:1586-

7661591.

767 Zhang J, Kumar S. 1997. Detection of convergent and parallel evolution at the amino acid

768 sequence level. Mol Biol Evol 14:527-536.

769 Zhou XM, Seim I, Gladyshev VN. 2015. Convergent evolution of marine mammals is associated

770 with distinct substitutions in common genes. Scientific Reports 5.

771 Zou Z, Zhang J. 2015. No genome-wide protein sequence convergence for echolocation. Mol

772 Biol Evol 32:1237-1241. 


\section{Figure 1}

Phylogenetic relationships among $64 \mathrm{C}_{4}$ and $\mathrm{C}_{3}$ grass species.

The phylogeny tree was obtained using RAxML (GTR $+\Gamma$ model) based on the third codon position sites in 67 chloroplast genes. The partitioning scheme was selected according to Akaike information criterion (AIC). $\mathrm{C}_{4}$ and $\mathrm{C}_{3}$ reference branches are shown in red and black, respectively. Red stars and black circles (labels $A-V$ ) indicate $C_{4}$ and $C_{3}$ reference branches, respectively. Numbers represent bootstrap support. 


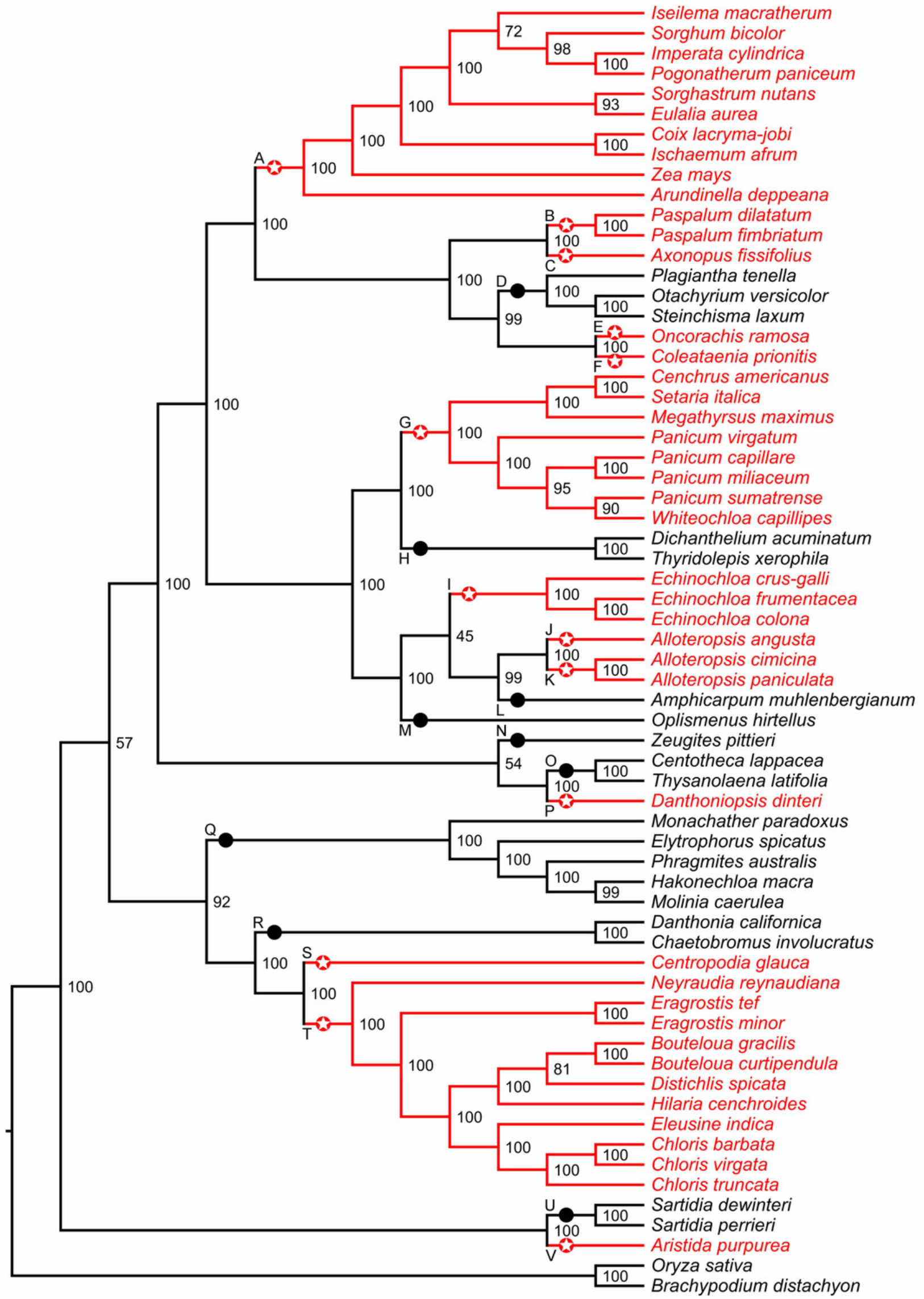




\section{Figure 2}

Example of $\mathrm{C}_{4}$ and $\mathrm{C}_{3}$ reference branches and convergent changes in $\mathrm{C}_{4}$ reference branches.

(A) PACMAD phylogeny and identification of reference branches. The $\mathrm{C}_{4}$ reference branches (highlighted by red circles with stars) contain the common ancestor of a clade with only $\mathrm{C}_{4}$ species (red lines). The $\mathrm{C}_{3}$ reference branches (highlighted by black circles) contain the common ancestor of a clade with only $\mathrm{C}_{4}$ species (black lines). $\mathrm{C}_{4}$ reference branches that are next to each other represent lineages that independently acquired the $C_{4}$ pathway and are separated by species with the $C_{3}$ pathway that were no included in this study because of the lack of complete chloroplast genomes. For each species, the $\mathrm{C}_{4}$ or $\mathrm{C}_{3}$ photosynthesis type was obtained from the Supplementary figure 1 in the Grass Phylogeny Working Group II (2012). (B) Amino acid replacements in the reference branches. The sequence of chloroplast proteins was inferred in each reference branch and compared to the inferred sequence in the branch ancestral to the reference branch. In this example, the amino acid 101 in the protein RbcL is represented by a Valine ( $\mathrm{V}$ ) in branches ancestral to all reference branches, but a convergent $\mathrm{V}$->I amino acid replacement occurred along the $\mathrm{C}_{4}$ reference branches $\mathrm{G}$, I and J. 
(A)

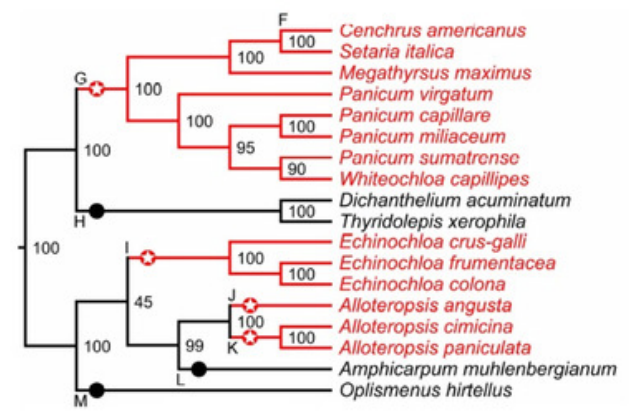

Phylogenetic reconstruction
(B)

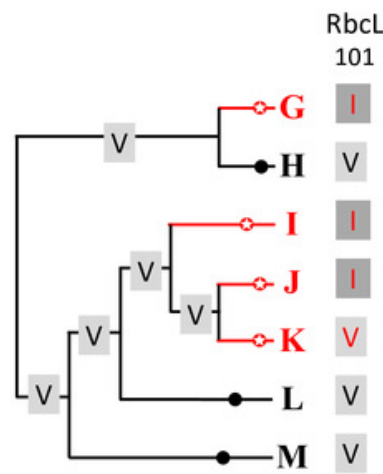

Replacements in ancestral branches 
Figure 3

Amino acid replacements shared by at least three $C_{4}$ or $C_{3}$ reference branches.

Ancestral (A) and derived (D) amino acids at replacement sites are shown. Site numbers correspond to the Zea maysorthologous sequence annotation. Red and black letters and branches represent $C_{4}$ and $C_{3}$ reference branches, respectively (see also Figs. 1 and 2).

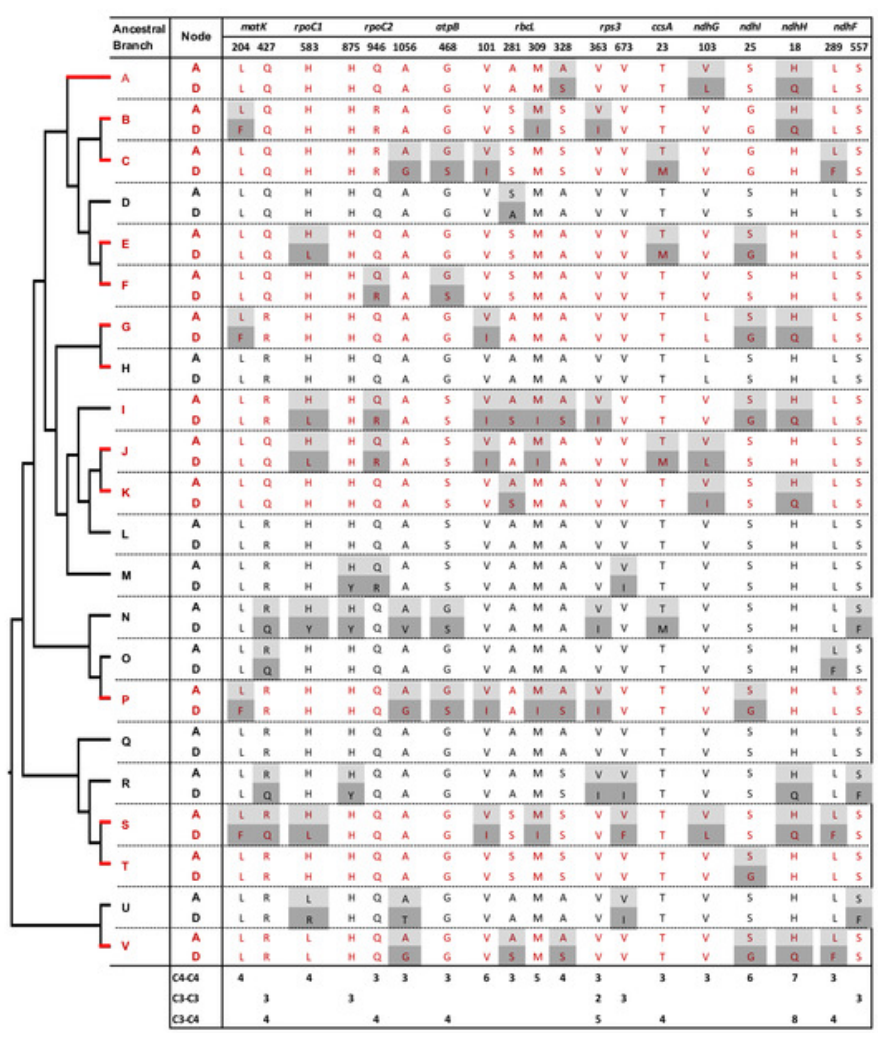


Figure 4

Distribution of convergent and non-convergent amino acid replacements in pairs of reference branches.

(A) $C_{4}: C_{4}$ pairs. (B) $C_{3}: C_{3}$ pairs. (C) $C_{3}: C_{4}$ pairs. NC: non-convergent.
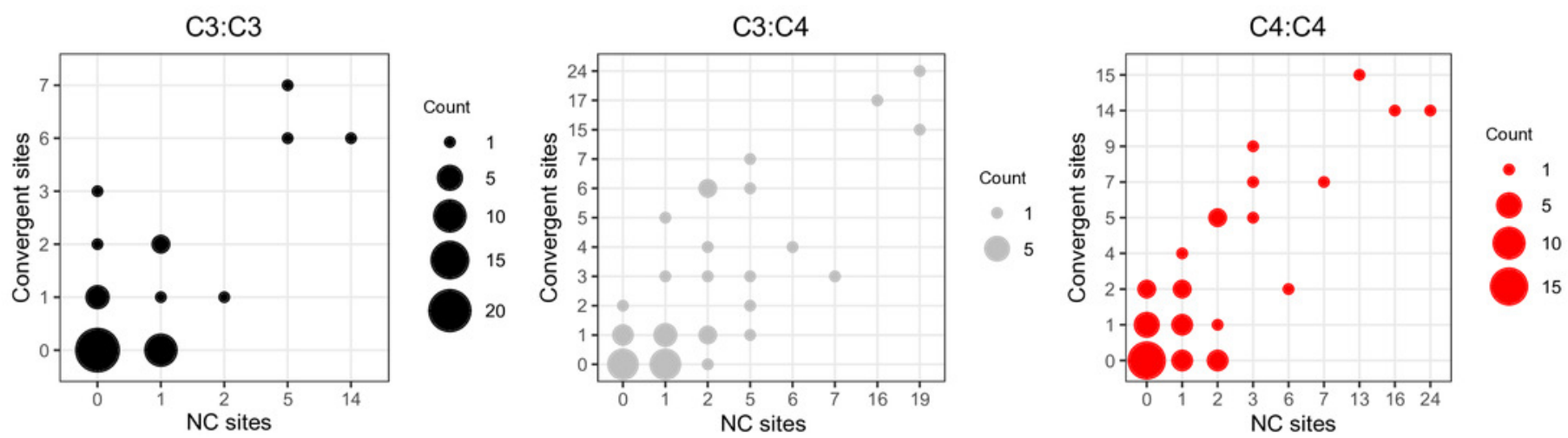
Figure 5

Amino acid replacements in chloroplast proteins with more convergent than nonconvergent changes.

Twenty-six chloroplast proteins with more convergent than non- convergent changes in $\mathrm{C}_{4}: \mathrm{C}_{4}$, $\mathrm{C}_{3}: \mathrm{C}_{4}$ and $\mathrm{C}_{3}: \mathrm{C}_{3}$ pairs.
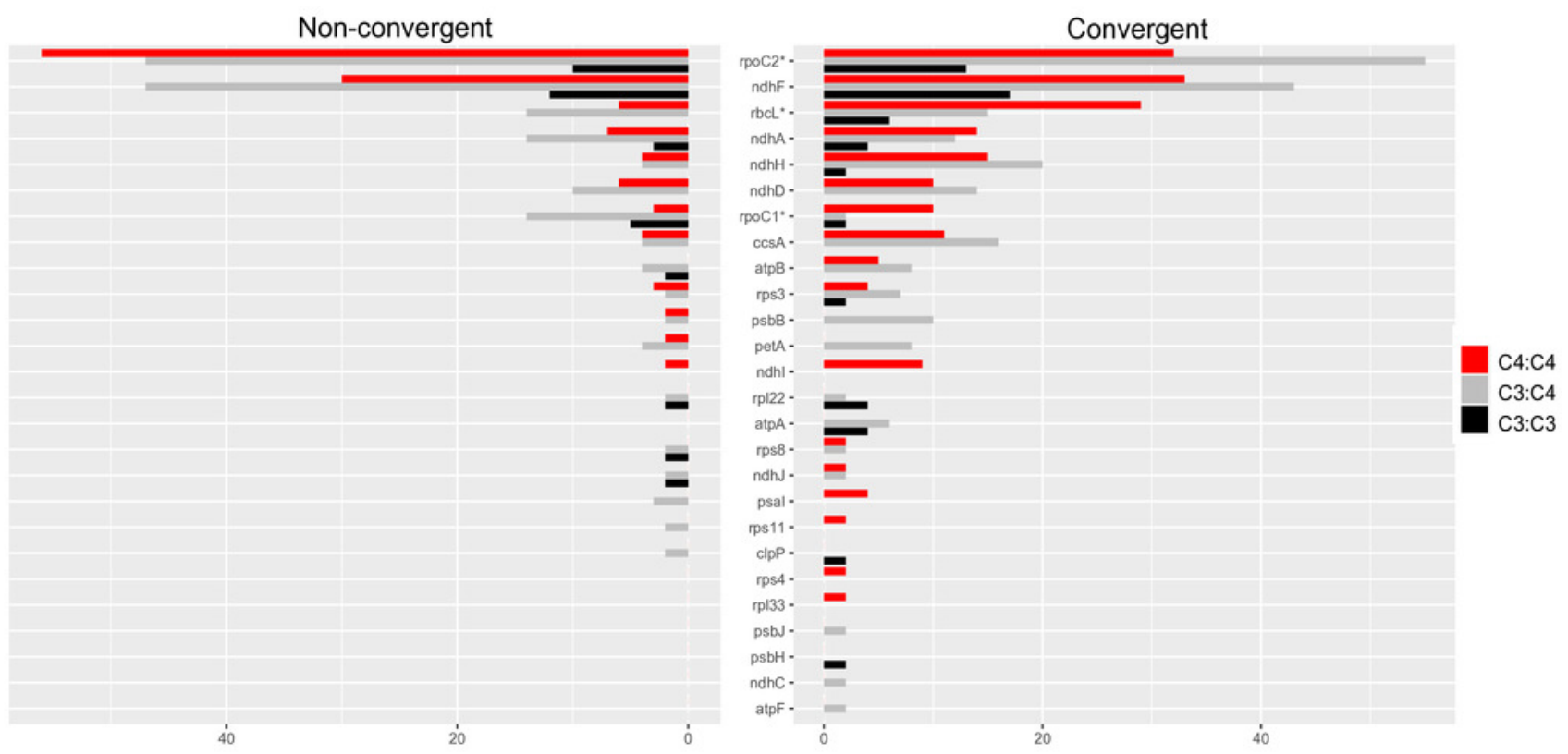


\section{Figure 6}

Pairs of reference branches by convergent and non-convergent replacements.

Difference in the number of pairs of reference branches for convergent and non-convergent categories (0-8 and 10 replacements).

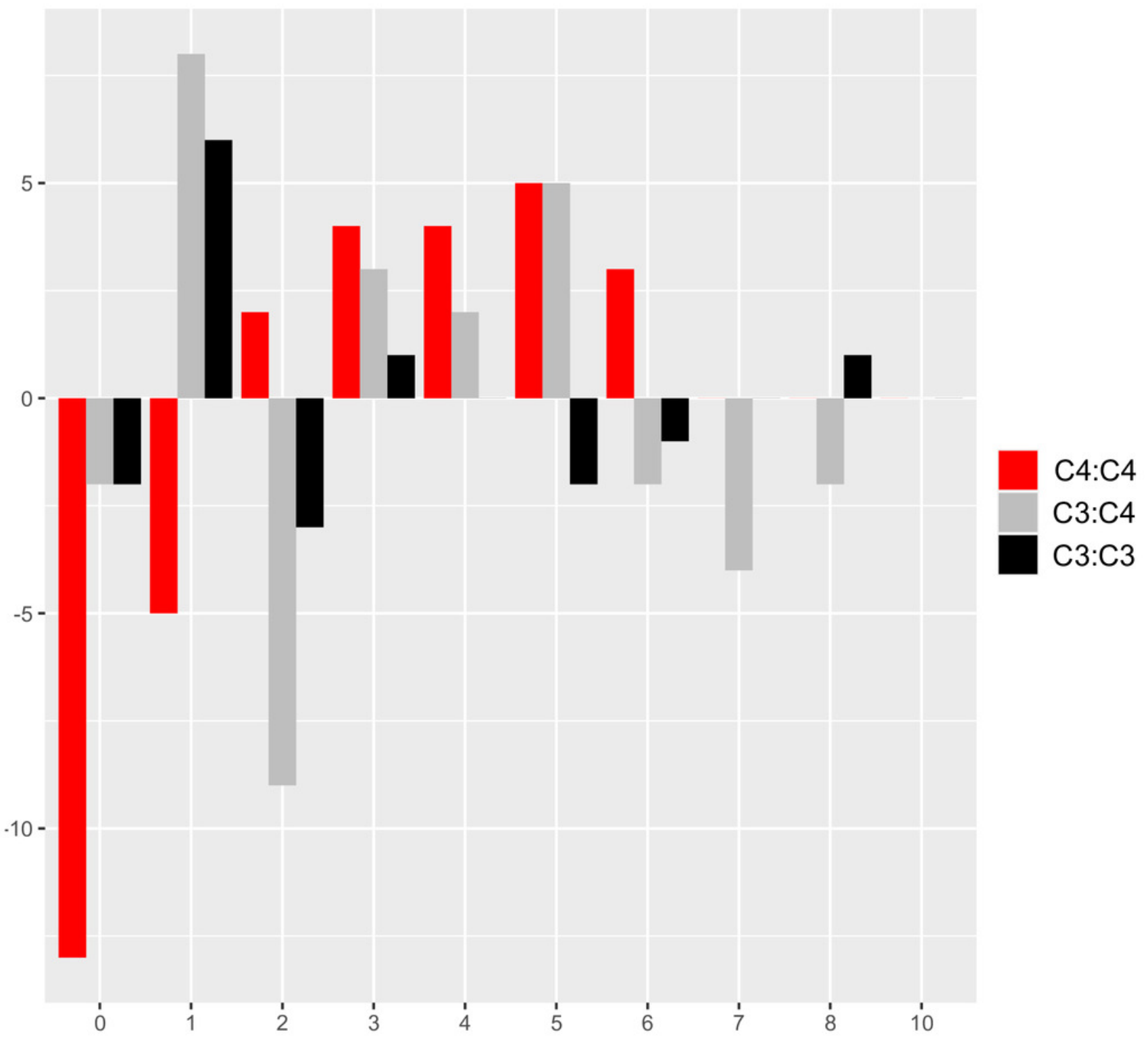




\section{Table $\mathbf{1}$ (on next page)}

Numbers of amino acid sites and genes with convergent and non-convergent replacements in reference branch comparisons.

Comparisons were made between pairs of $\mathrm{C}_{4}: \mathrm{C}_{4}, \mathrm{C}_{3}: \mathrm{C}_{3}$ and $\mathrm{C}_{3}: \mathrm{C}_{4}$ branches. Numbers of replacements unique to a given category $(*)$, and the corresponding ratios Con:NC (Ratio). Differences between the $C_{3}: C_{3}$ and $C_{4}: C_{4}$ categories are not statistically significant $(P \geq 0.05$, Boschloo's test). Con: convergent. NC: non-convergent. 


\begin{tabular}{lrrrrrrrrr}
\hline & \multicolumn{3}{c}{$\mathbf{C}_{\mathbf{4}}: \mathbf{C}_{\mathbf{4}}$} & \multicolumn{3}{c}{$\mathbf{C}_{\mathbf{3}}: \mathbf{C}_{\mathbf{4}}$} & \multicolumn{3}{c}{$\mathbf{C}_{\mathbf{3}}: \mathbf{C}_{\mathbf{3}}$} \\
& Con & NC & Ratio & Con & NC & Ratio & Con & NC & Ratio \\
\hline Sites & 104 & 96 & 1.08 & 120 & 121 & 0.99 & 34 & 39 & 0.87 \\
Sites* & 80 & 64 & 1.25 & 82 & 69 & 1.19 & 17 & 16 & 1.06 \\
Genes & 24 & 23 & 1.04 & 26 & 32 & 0.81 & 13 & 17 & 0.76 \\
Genes* & 24 & 20 & 1.2 & 25 & 29 & 0.86 & 9 & 10 & 0.9 \\
\hline
\end{tabular}

1 


\section{Table 2 (on next page)}

Number of reference branches with convergent and non-convergent replacements.

Comparisons were made between pairs of $\mathrm{C}_{4}: \mathrm{C}_{4}, \mathrm{C}_{3}: \mathrm{C}_{3}$ and $\mathrm{C}_{3}: \mathrm{C}_{4}$ branches. Proportions of pairs of reference branches over all branches by category are shown in parenthesis. The total number of pairs of reference branches are 78,36 and 117 for $\mathrm{C}_{4}: \mathrm{C}_{4}, \mathrm{C}_{3}: \mathrm{C}_{3}$ and $\mathrm{C}_{3}: \mathrm{C}_{4}$ comparisons, respectively. All comparisons between $C_{4}: C_{4}$ pairs and both $C_{3}: C_{3}$ and $C_{3}: C_{4}$ pairs were statistically significantly different ( $P<0.05$, Boschloo's test). No comparison between $\mathrm{C}_{3}: \mathrm{C}_{3}$ and $\mathrm{C}_{3}: \mathrm{C}_{4}$ pairs was statistically significant $(P \geq 0.05$, Boschloo's test). Con: convergent. NC: non-convergent. Con>NC: pairs of branches with more convergent than non-convergent replacements. Con>1: pairs of branches with more than one convergent replacement. 


\begin{tabular}{lrcc}
\hline & $\mathbf{C}_{\mathbf{4}}: \mathbf{C}_{\mathbf{4}}$ & $\mathbf{C}_{\mathbf{3}}: \mathbf{C}_{\mathbf{4}}$ & $\mathbf{C}_{\mathbf{3}}: \mathbf{C}_{\mathbf{3}}$ \\
\hline No replacements & $6(.08)$ & $30(.26)$ & $12(.33)$ \\
No Con & $12(.15)$ & $48(.41)$ & $16(.44)$ \\
w/Con & $66(.85)$ & $69(.59)$ & $20(.56)$ \\
w/NC & $63(.81)$ & $67(.57)$ & $18(.50)$ \\
Con $>\mathrm{NC}$ & $40(.51)$ & $36(.31)$ & $10(.28)$ \\
Con $>1$ & $49(.63)$ & $39(.33)$ & $8(.22)$ \\
\hline
\end{tabular}

1 


\section{Table 3 (on next page)}

Table 3. Summary of RbcL amino acid sites with signatures of convergent evolution or positive selection.

Ancestral AA: ancestral amino acid. Convergent change/p.s.s.: derived amino acid in multiple $\mathrm{C}_{4}$ reference branches and positively selected sites from previous studies. \#Convergent a.b.: number of reference branches with convergent changes. Boldface: sites with convergent changes identified in this study. Asterisk: positively selected sites in PACMAD $\mathrm{C}_{4}$ lineages from Christin et al. (2008). Dagger: positively selected sites in PACMAD $C_{4}$ lineages from Piot et al. (2018). 


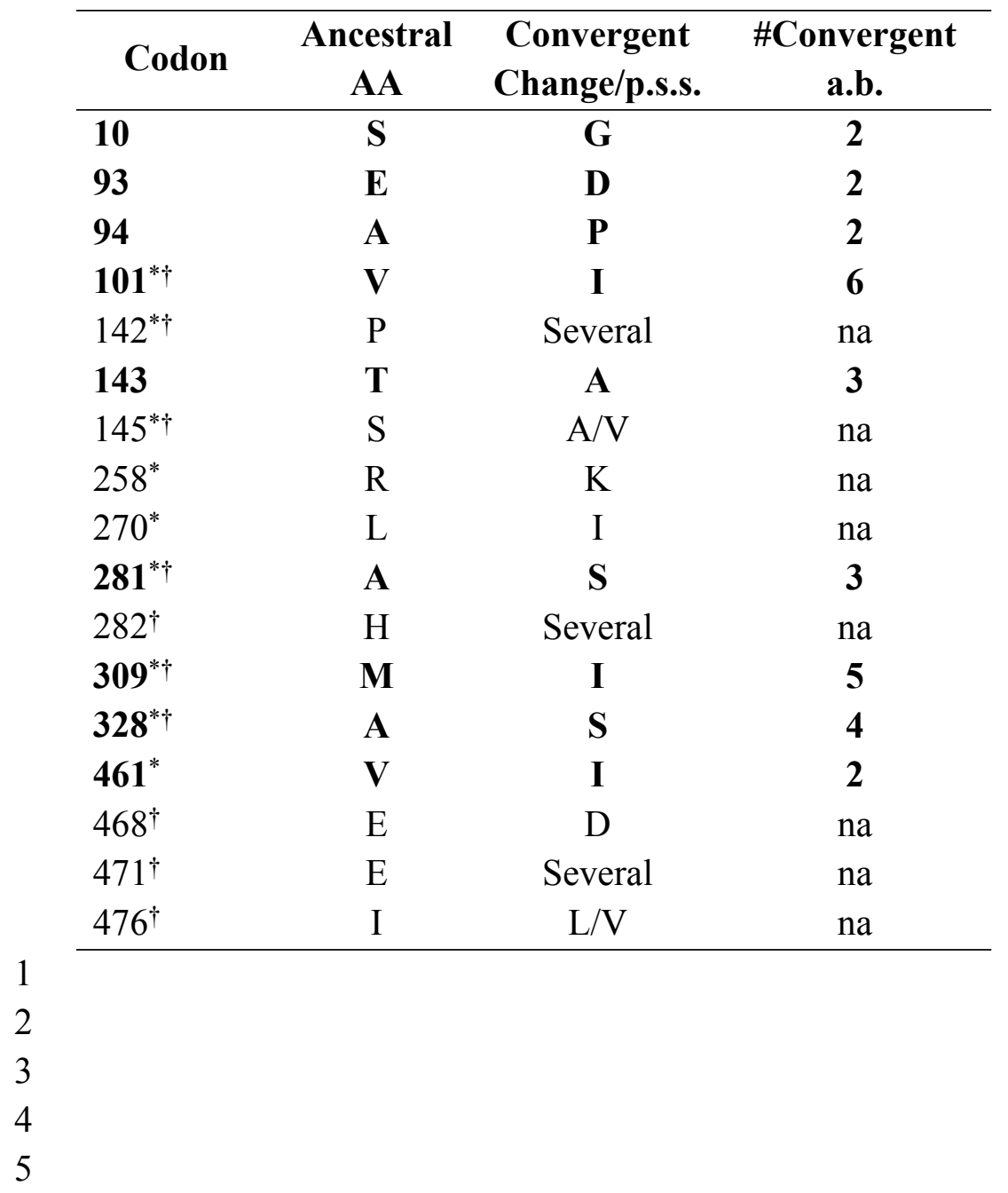

